\title{
Efficient Transformerless MOSFET Inverter for Grid-Tied Photovoltaic System
}

\author{
M. Mareeswari ${ }^{1}$, K. Ramalakshmi ${ }^{2}$, A. Saranya ${ }^{3}$, B. Noorul Hamitha ${ }^{4}$ \\ UG student, Department of Electrical and Electronics Engineering, Kamaraj College of Engineering and Technology, \\ Virudhunagar, Tamilnadu, India ${ }^{1,2,3}$ \\ Assistant Professor, Department of Electrical and Electronics Engineering, Kamaraj College of Engineering and \\ Technology, Virudhunagar, Tamilnadu, India ${ }^{4}$
}

\begin{abstract}
The grid tied photovoltaic system suffers a great loss because the perormance of the transformer present in the inverter. The cost of the transformr is high and the maintaince cost is also high.Therefore transformerless inverter are widely used in grid tied photovoltaic system,due to the benefits of achieving high efficiency and low cost. The sinusoidal pulse width modulation of full bridge transformerless inverters can achieve high effeciency by using metal oxide semiconductor field effect transistor. Various topology has been implemented for transformerless inverter, but in that there is a problem of losse and reverse recovery characteristics. In our paper we are going to implement the centre tapped $\mathrm{H}$ bridge transformerless inverter topology for grid tied photovoltaic system to avoid the losses and leakage current. A clamped branch is added in the transformerless inverter. The added clamping branch clamps the freewheeling voltage at the freewheeling period. As the common mode voltage is kept constant for the whole grid period that reduce the leakage current. The splitting structure of inductor at the region of grid side avoids reverse recovery voltage and this improves the effeciency of the system. The detailed analysis of our topology with the operational modes, leakage current analysis and design consideration were implemented.
\end{abstract}

Keywords: Transformerless; Photovoltaic; Grid connected; Efficiency.

\section{INTRODUCTION}

Recently, transformerless inverter has been found as one of the excellent solution for grid-tied PV application because of its higher conversion efficiency, lower cost, smaller size, and light weight if compare with one's consist transformer. Important concern of transformerless inverter is the efficiency that can be improved by optimal design. Most of the inverters described in the literature and commercially available show the European efficiency in the range of $96 \%-98 \%$. This issue(efficiency ) are the major force in pushing progressive development of transformerless grid-tied PV inverter.

The CM voltage needs to be clamped to the mid-point of dc input voltage instead of only disconnecting the PV module from the grid. On the other hand, to improve the efficiency, transformerless inverter can be implemented using super-junction MOSFET and $\mathrm{SiC}$ diodes. The super-junction MOSFETs can avoid the fixed voltage drop and turn-off losses caused by tail current, thereby reducing the conduction and switching losses.

However, due to poor reverse recovery of MOSFETs slow body-diode, it is limited to use in transformerless inverter. In the following, MOSFET based transformerless topologies for grid-tied PV application will be reviewed and discussed based on their circuit structure, efficiency and $\mathrm{CM}$ voltage clamping capability.

\section{Simulation explanation}

The most attractive transformerless topology is the Highly Efficient and Reliable Inverter concept (HERIC) topology is mostly used commercia; inverter. Here we are modifying HERIC topology by eliminating the switches and including freewheeling diodes. In this topology we give 420V DC supply to the switches S1 and S4 when the gate pulse is given to them through PWM technique and the switches get open based on the time period given to them. A time delay is given, at that time every switches are in open condition. After a time delay, switches S2 and $\mathrm{S} 3$ are closed. This get repeated, to attain $50 \mathrm{~Hz} 420 \mathrm{~V}$ AC supply. The freewheeling diode acts at the time when the source is cut-off. The center tapped free wheeling path of the diode reduce the leakage current losses as well as freewheels the voltage this concept is helpful in the side of ON grid configuration by improving efficiency and eliminate the losses. This improves the efficiency of the system and isolate the load side from source side.

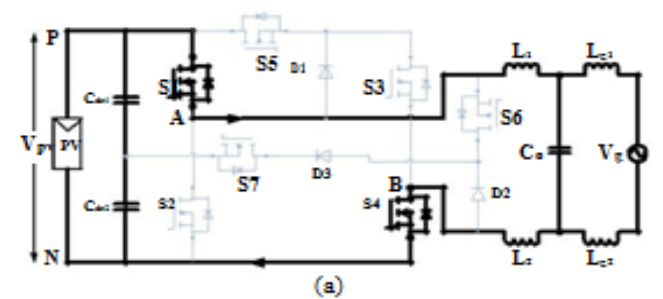




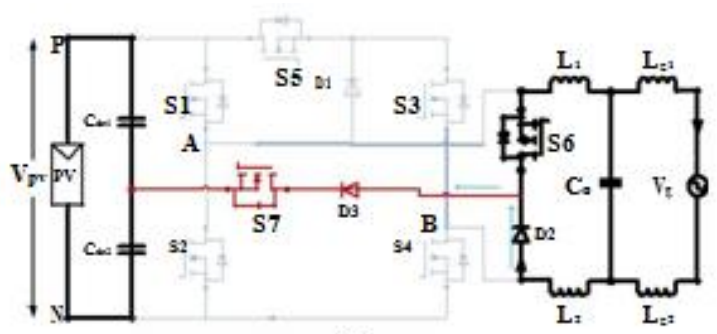

(b)

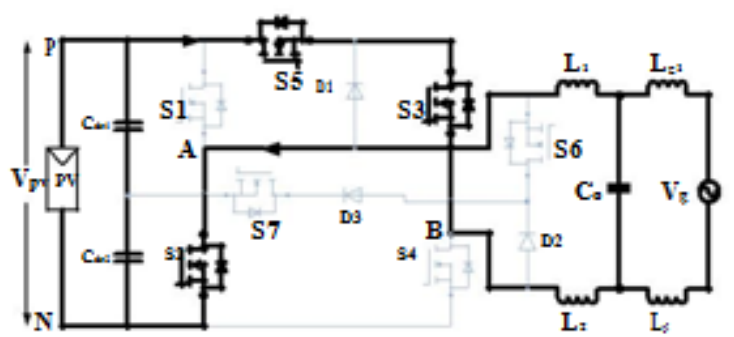

(c)

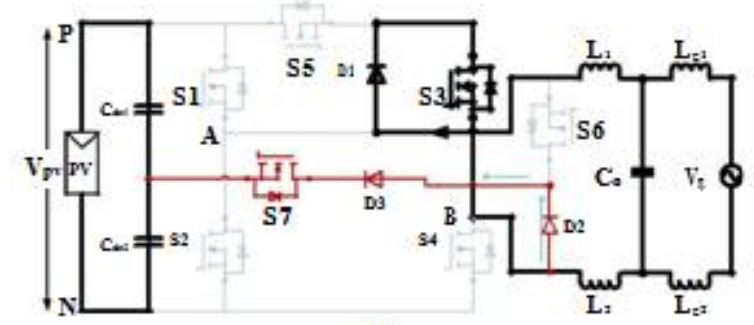

(d)

Figure 1: Operating principle: (a) active and (b) freewheeling mode in positive half cycle; (c) active and

(d) freewheeling mode in negative half cycle.

\section{PROPOSED TOPOLOGY}

\section{Operating Principle:}

In order to analyse and verify, the circuit structure (a) is taken as an example, it shows the switching pattern for unity power factor operation, where the G1, G2, G3, G4, G5, G6 and G7 are the gate signals of the switches S1, S2, S3, S4, S5, S6 and S7. As can be seen, (S1, S4) and (S2, S5) commutate at the switching frequency with the identical commutation order in the positive and negative half cycle of the grid current, respectively. The operating principles of the proposed topology are shown. Four operation modes are proposed to generate the output voltage stste of $+\mathrm{Vpv}, 0$ and $-\mathrm{Vpv}$, which can explained as follows.

1) Mode 1 is the active in the positive half cycle of the grid current.When S1,S4 are turned-on, the inductor current $i_{L}$ increases linearly through grid. In this mode, $\mathrm{V}_{\mathrm{AN}}=\mathrm{V}_{\mathrm{PV}}$ and $\mathrm{V}_{\mathrm{BN}}=0$, thus $\mathrm{V}_{\mathrm{AB}}=\mathrm{V}_{\mathrm{PV}}$ and the inductor current:

$$
\mathbf{i}(\mathbf{t})=\frac{\mathbf{V p v}-\mathbf{V g}}{\mathbf{L}}(\mathbf{t})
$$

2) Mode 2 is the freewheeling mode in the positive half cycle of the grid current. The inductor current $i_{L}$ flows though S6 and D2, and reduces linearly under the effect of grid voltage. In this state, $\mathrm{V}_{\mathrm{AN}}$ falls and $\mathrm{V}_{\mathrm{BN}}$ rises until their values are equal. If the voltages $\left(\mathrm{V}_{\mathrm{AN}} \approx \mathrm{V}_{\mathrm{BN}}\right)$ are higher than half of the dc link voltage, freewheeling current flows through S7 \& D3 to the midpoint of the dc link, results $\mathrm{V}_{\mathrm{AN}}$ and $\mathrm{V}_{\mathrm{BN}}$ are clamped at $\mathrm{V}_{\mathrm{PV}} / 2$. Therefore , at mode $2, \mathrm{~V}_{\mathrm{AN}}=\mathrm{V}_{\mathrm{PV}} / 2, \mathrm{~V}_{\mathrm{BN}}=\mathrm{V}_{\mathrm{PV}} / 2$, the inverter output voltage $\mathrm{V}_{\mathrm{AB}}=0$ and the inductor current:

$$
\mathbf{i}(\mathbf{t})=\frac{-\mathbf{V g}}{\mathbf{L}}(\mathbf{t})
$$

3) Mode 3 is the active mode in the negative half cycle of grid current. Similar to mode 1, when S2, S3, and $\mathrm{S} 5$ are turned-on, the voltage $\mathrm{V}_{\mathrm{AN}}=0$ and $\mathrm{V}_{\mathrm{BN}}=\mathrm{V}_{\mathrm{PV}}$, thus $\mathrm{V}_{\mathrm{AB}}=-\mathrm{V}_{\mathrm{PV}}$ and the inductor current:

$$
\mathbf{i}(\mathbf{t})=\frac{\mathbf{V p v}-\mathbf{V g}}{\mathrm{L}}(\mathbf{t})
$$

4) Mode 4 is the freewheeling mode in the negative half cycle of grid current. When S5 and S2 are turned-off, the inductor current flows throgh S3 and D1. Similar to mode 2, if the voltages $\left(\mathrm{V}_{\mathrm{AN}}=\mathrm{V}_{\mathrm{BN}}\right)$ are higher than half of the dc link voltag, freewheeling current flows through S7 and D3 to the mid-point of the dc link, results the voltages $\mathrm{V}_{\mathrm{AN}}$ and $\mathrm{V}_{\mathrm{BN}}$ are clamped at $\mathrm{V}_{\mathrm{PV}} / 2$. Therefore, in this mode, $\mathrm{V}_{\mathrm{AB}}=0$, and the inductor current:

$$
\mathbf{i}(\mathbf{t})=\frac{-\mathbf{v g}}{\mathbf{L}}(\mathbf{t})
$$

As described above, the freewheeling path potential is clamped at the mid-point of the dc link during freewheeling period of positive and negative half cycle. As a result, the seen that the anti-parallel diodes of the MOSFETs remained inactive during the whole grid operation period. Therefore, the proposed could be implemented utilizing MOSFET switches. However, the body-diode will be activated if a phase shift is occurred in the inverter output voltage and current. Accordingly, the dependability of the system will be reduced becauce of the MOSFET anti-parallel diode low reverse recovery issues.

\section{BLOCK DIAGRAM AND ITS BRIEF DESCRIPTION}

The project work 'Transformer less inverter for grid tied PV system' focus mainly on the transformer less operation in grid tied PV system. The block diagram explains about input and output terminals of our project. The function of the solar panel and grid connected transformer less inverter are explained.

\section{Solar Panel}

Solar plays a major role in the generation of electricity. Solar energy is radiant light and heat from the sun. Solar energy is the conversion of sunlight into electricity using photovoltaic system. A solar cell is a device that converts light directly into electricity using photoelectric effect. Solar cell is a semiconductor device. A semiconductor material is placed between two electrodes. When the sunrays reach the cell, free negative charge electrons discharge from the cell and convert to electricity. This is known as photovoltaic effect. Most commonly high 
purified silicon is used to convert sunlight directlyinto electricity. In grid connected system there is no need for storage of energy. The advantage of the grid tied photovoltaic system is the net metering. Solar panel is deigned to absorb sun's rays. A photovoltaic module is a connected assembly of $6 * 10$ solar cell. The modules are connected in series to achieve a desired output voltage.

\section{Solar Inverter}

Solar inverter is differ from the normal conventional inverter. The solar inverter can be OFF grid, ON grid, Hybrid connected grid.A grid tied or ON grid inverter is a power inverter that converts direct current electricity into alternate current with an ability to synchronize to interface with a utility line. In solar PV system transformer is used to step-up the voltage levelbut this increase the size and produce more losses. Transformerless inverters is widely used nowadays in order to reduce the cost and to increase the efficiency. Employing this technology of direct inversion is achieved using array of panel strings. Not only offer a efficient method of generating power, it eliminates inverter centric transformer, balance of system cost, as well as unnecessary wiring losses. Traditional inverter work through only one power point, which means panels that are performing at low frequencies will lower dc output for entire system. But it is not in the case of solar inverter. In grid tied inverter they can sell the extra electricity generated back to the distributed area. Grid tied inverters are designed to shut down automatically upon losses of utility supply.

\section{Block diagram}

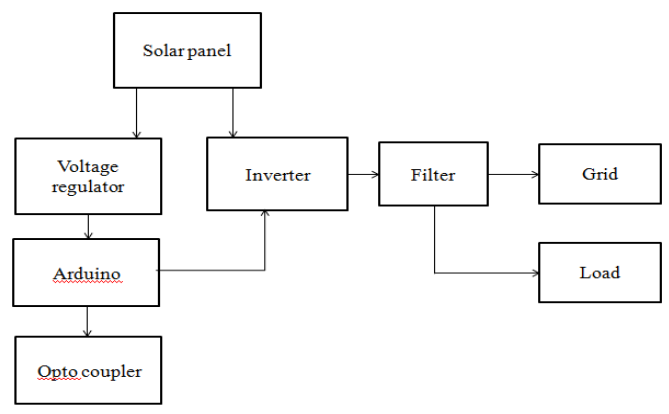

Figure:2 Experimental block diagram

\section{Opto coupler}

In electronics, an optocoupler, also called an opto-isolator, photocoupler, or optical isolator is a component that that transfers electrical signals between two isolated circuits by using light. Optocoupler prevent high voltage from affecting the system receiving the signal. A common type of optocoupler consists of an LED and a phototransistor in the same opaque package. An opto-isolator contains a source of light, almost always a near infrared LED, that converts electrical input signals into light, a closed optical channel and a photo sensor, which detects incoming light and either generates electric energy directly, or modulates electric current flowing from an external power supply. The sensor can be a photoresistor, a phototransistor, a silicon-controlled rectifier or a triac. Becauce LEDs can sense light in addition to emitting it, construction of symmetrical, bidirectional opto-isolator which drives a power switch, usually a complementary pair of MOSFETs. A slotted switch contains a source of light and a sensor, but its optical channel is open, allowing modulation of light by external objects obstructing the path of light reflecting light into the sensor. A circuit can also incoporate high voltages by design, in which case it needs safe, reliable means of interfacing its high-voltage components with low-voltage.

\section{Arduino}

Arduino is a open source electronics platform based on easy to use hardware and software. Arduino is based on Atmega328.Thearduino boards are inexpensive compared to other microcontroller platform. The arduino requires $5 \mathrm{~V}$ as input voltage to operate and it is gviven through battery or through adaptor. There is 14pins of digital input and output where the $14^{\text {th }}$ pin is the ground pin. There is a reset button in order to restart the program and there is a USB socket to feed the program to the arduino from the system. The arduino UNO possess number of facilities for communicating with a computer, another arduino or another microprocessor. Once the program is uploaded then the arduino begins to perform the operation as per the program. The program code is checked before it executed.They possess $16 \mathrm{MHZ}$ crystal oscillator.In arduinobased on the program of the switching control of mosfet helps to provide dc to ac voltage in the inverter which is programmed to produce $50 \mathrm{HZ}$ frequency.In our project arduino is used to control the MOSFET switching operation. The gate pulse is given to the MOSFET from the arduino. Based on the switching pulse the mosfet are operated that produce the alternating current. The arduino is connected to the 4 mosfet and they operate by switch $\mathrm{ON}$ the mosfet in one limb and the another mosfet in the next limb in order to close the circuit.

\section{In Grid connected system}

In general there is 3 types of interconnected system. They are ON grid, OFF grid and hybrid connected system. In OFF grid there is no direct connection of the generation region to the distribution side.This system is mainly followed in India because of the frequent power failure it is unable to follow the $\mathrm{ON}$ grid system. They mainly depend on the storage system. There is a large leakages while storing in the battery. This reduce the efficiency of the system. The $\mathrm{ON}$ grid possess more advantage compared to the other. Because they directly connect the generation and the utility side without requirement of any storage system. Therefore the losses are minimum. But in this case the generation region could synchronize the grid side in order to match the frequency and voltage in the grid side. The grid tied system is simple and easy to install. From this system the extra generate power can be sell to other customers and this reduce the electricity bill to the energy givers. In our project we are going to connect the solar output to the grid tied inverters which 
convert DC energy from the renewable source to the AC energy where there is no need of storage element.

\section{Simulation implementation}

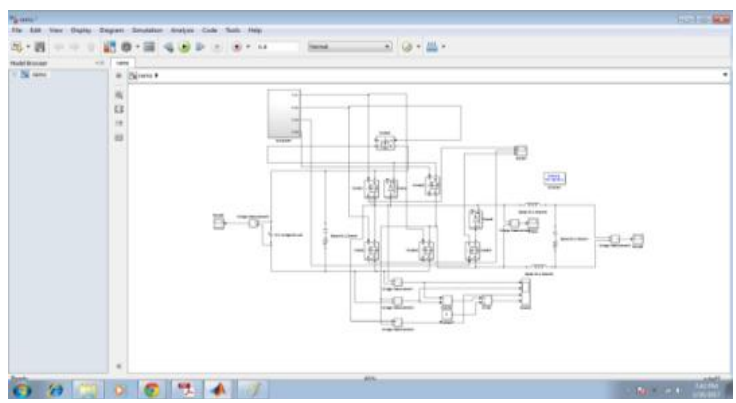

Figure:3 Simulation for eliminating losses

\section{Simulation result}

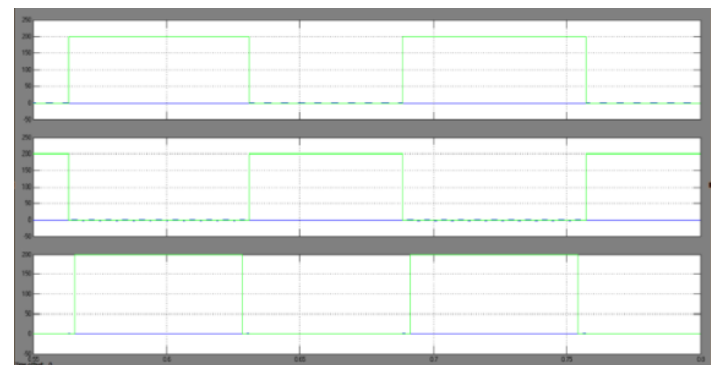

Figure:4 Gate signals

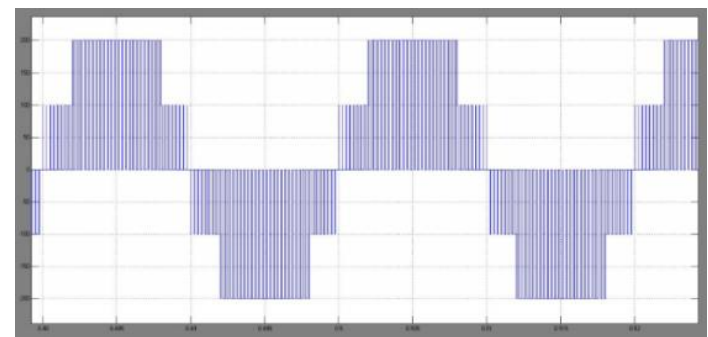

Figure:5 Clipping of squre wave

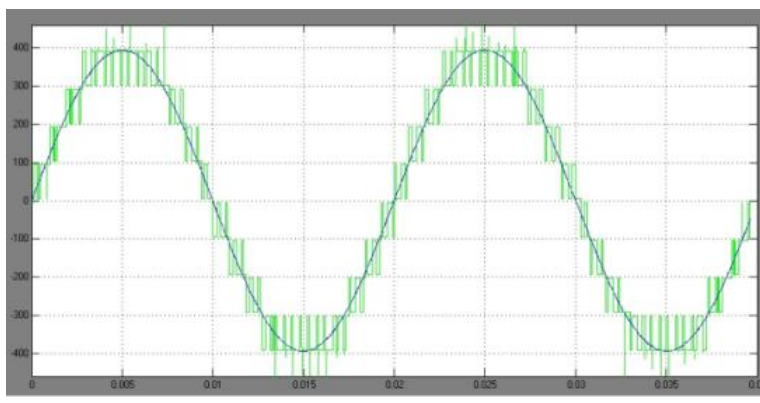

Figure:6 Output of AC side

\section{Hardware implementation}

The $110 \mathrm{~V}$ DC is obtained by connecting $12-18 \mathrm{~V}$ range 7 Panels in series. From the panel $12-18 \mathrm{~V}$ supply is taken separately which is given as the input to arduino through voltage regulator(7805) because the arduino requires only $5 \mathrm{~V}$ supply. This arduino provide gate signal to the MOSFET through the optocoupler which requires $12 \mathrm{~V}$ to operate which is taken from the $12 \mathrm{~V}$ voltage regulator(7812). When the arduino provides the gate signal, the optocoupler sense the signal and it is given to gate of the MOSFET. When the gate signal is applied, the $110 \mathrm{~V}$ Dc supply is directly enter inside the MOSFET. From the MOSFET inverter $50 \mathrm{~Hz} 110 \mathrm{~V}$ Ac voltage is obtained. The obtained output is not a pure sinusoidal wave. In order to achieve this, multilevel inverter is designed. In general from the solar, it is not possible to obtain pure sine wave. So, the advantage is it reduces cost effective, losses and amount of heat.

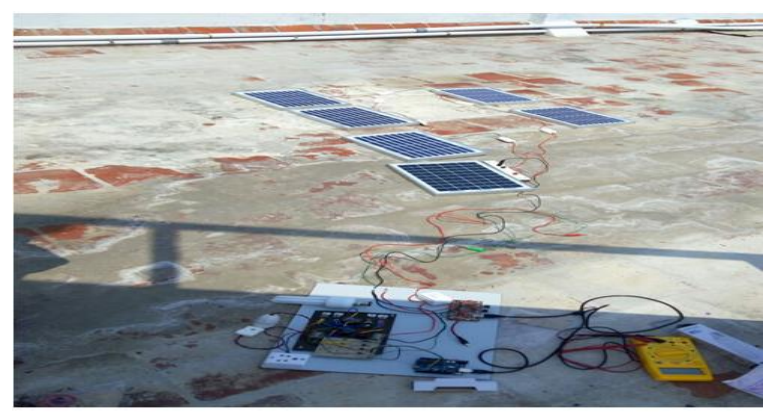

Figure:7 110V Solar implementation hardware

\section{Hardware result}

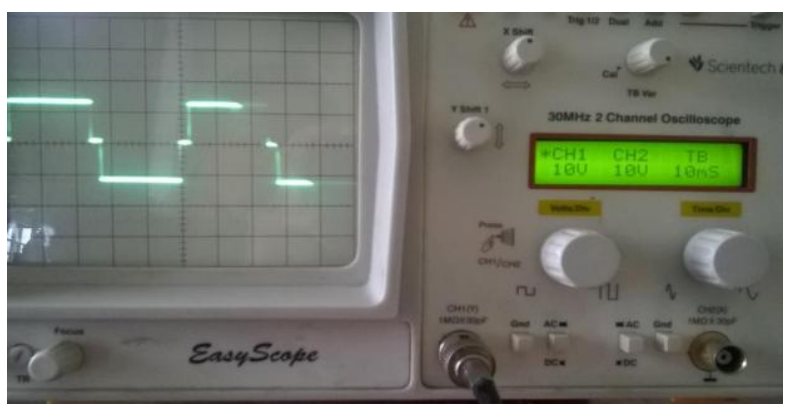

Figure:8 Clipping of squre wave in hardware

Table 1

\begin{tabular}{|c|c|}
\hline Parameters & Values \\
\hline Input voltage & $110 \mathrm{~V} \mathrm{DC}$ \\
\hline Grid voltage & $110 \mathrm{~V} / 50 \mathrm{~Hz}$ \\
\hline Rated power & $500 \mathrm{~W}$ \\
\hline Filter capacitor & $0.9 \mu \mathrm{F}$ \\
\hline MOSFET & IRF840,IRF9640 \\
\hline Transistor & BF420 \\
\hline Optocoupler & BC817 \\
\hline Regulator & 7805,7812 \\
\hline Arduino & $\mathrm{UNO}$ \\
\hline Resistor & $2 \mathrm{~K} 2,10 \mathrm{~K}, 100 \mathrm{R}, 47 \mathrm{~K}, 1 \mathrm{~K}$ \\
\hline
\end{tabular}

\section{CONCLUSION}

In this paper, a family of new efficient transformerless inverter for grid-tied photovoltaic power generation system is presented using super-junction MOSFETs as main power switches. The main advantages of the 
proposed topology are as follows: (1) High efficiency over a wide load range is achieved by using MOSFETs and SiC diodes, (2) Like as isolated full-bridge inverter, excellent DM characteristics are achieved with unipolar SPWM, (3) PWM dead time is not required for main power switches, results low distortion at output. Finally, the proposed topology has been validated by a prototype rated $240 / 50 \mathrm{~Hz}, 1 \mathrm{~kW}$. The experimental results show $98.5 \%$ maximum efficiency and $98.32 \%$ European efficiency. Therefore, it can be concluded that the proposed inverter is very suitable for a single-phase grid-tied PV application.

\section{REFERENCES}

[1] M. Islam, S. Mekhilef, and M. Hasan, "Single phase transformerless inverter topologies for grid-tied photovoltaic system: A review," Renewable and Sustainable Energy Reviews, vol. 45, pp. 69-86, 2015.

[2] I. Patrao, E. Figueres, F. González-Espín, and G. Garcerá, "Transformerless topologies for grid-connected single-phase photovoltaic inverters," Renewable and Sustainable Energy Reviews, vol. 15, pp. 3423-3431, 2011.

[3] Z. Li, S. Kai, F. Lanlan, W. Hongfei, and X. Yan, "A Family of Neutral Point Clamped Full-Bridge Topologies for Transformer Photovoltaic Grid-Tied Inverters," IEEE Transactions on Power Electronics, vol. 28, pp. 730-739, 2013.

[4] M. Islam and S. Mekhilef, "H6-type transformerless single-phase inverter for grid-tied photovoltaic system," IET Power Electronics, vol. 8, pp. 636-644, 2015.

[5] J. Baojian, W. Jianhua, and Z. Jianfeng, "High-Efficiency Single Phase Transformerless PV H6 Inverter With Hybrid Modulation Method," IEEE Transactions on Industrial Electronics, vol. 60, pp. 2104-2115, 2013.

[6] D. Barater, G. Buticchi, E. Lorenzani, and C. Concari, "Active Common-Mode Filter for Ground Leakage Current Reduction in Grid-Connected PV Converters Operating With Arbitrary Power Factor," IEEE Transactions on Industrial Electronics, vol. 61, pp. 3940-3950, 2014.

[7] T. Kerekes, R. Teodorescu, P. Rodriguez, G. Vazquez, and E.Aldabas, "A New High-Efficiency Single-Phase TransformerlessPV Inverter Topology," IEEE Transactions on Industrial Electronics, vol. 58, pp. 184-191, 2011.

[8] G. Bin, J. Dominic, L. Jih-Sheng, C. Chien-Liang, T. LaBella, and C. Baifeng, "High Reliability and Efficiency Single-Phase Transformerless Inverter for Grid-Connected PhotovoltaicSystems," IEEE Transactions on Power Electronics, vol. 28, pp. 2235-2245, 2013.

[9] Y. Bo, L. Wuhua, G. Yunjie, C. Wenfeng, and H. Xiangning, "Improved Transformerless Inverter With Common-Mode Leakage Current Elimination for a Photovoltaic Grid-Connected Power System," IEEE Transactions on Power Electronics, vol. 27, pp. 752$762,2012$.

[10] H. Guofeng, X. Dehong, and C. Min, "A Novel Control Strategy of Suppressing DC Current Injection to the Grid for Single-Phase PVInverter," IEEE Transactions on Power Electronics, vol. 30, pp.1266-1274, 2015. 